\title{
Feasibility of virtual mock trials as a parallel teaching-assessment activity for student pharmacists at two American pharmacy programmes during the COVID-19 pandemic and beyond
}

\author{
Shih-Ying H. Hsu 1, Ettie Rosenberg 1, Hoai-An Truong 2, Lynn Lang 2, Reza Taheri 3 \\ 1 West Coast University School of Pharmacy, Los Angeles, California, USA \\ 2 University of Maryland Eastern Shore, School of Pharmacy and Health Professions, Princess Anne, Maryland, USA \\ ${ }^{3}$ Chapman University, School of Pharmacy, Orange, California, USA
}

Keywords
Active Learning
COVID-19
Debate
Mock Trials
Technology
Virtual
Correspondence
Shih-Ying H. Hsu, PhD, RPh
Adjunct Assistant Professor
Department of Pharmacy Practice
West Coast University School of Pharmacy
590 N. Vermont Avenue
Los Angeles
California 90004
USA
ahsu@westcoastuniversity.edu

Keywords

Active Learning

Mock Trials

Technology

Correspondence

Shih-Ying H. Hsu, PhD, RPh

Adjunct Assistant Professor

West Coast University School of Pharmacy

590 N. Vermont Avenue

California 90004

ahsu@westcoastuniversity.edu

\begin{abstract}
Background: Student-pharmacists forced into remote-learning by the COVID-19 pandemic participated in a Virtual Mock Trial (VMT). Objectives: Feasibility of VMTs was assessed by evaluating student VMT performance, student perceptions on technology and overall experiences. Methods: The VMT was implemented via video conferencing technology in April 2020. Faculty-judges and student-jurors observed/rated student performance using pre-established rubrics. A post-VMT survey was administered electronically. Descriptive analyses were performed, and WilcoxonMann-Whitney tests were conducted to compare programmes. Results: Fortysix students from Programme A (East Coast, USA) and 89 from Programme B (West Coast, USA) participated in the VMTs. The faculty-judges' evaluation scores for student performance ranged from $85.0 \%$ to $96.7 \%$, while the student-jurors' evaluation scores ranged from $68.3 \%$ to $100 \%$. Student perceptions on the four categories regarding technology use all had means $>5$ on a 7-Point Likert Scale. More than $79.0 \%$ of students rated their VMT experience positively (i.e. 6 or 7). Conclusions: VMT is feasible for the current pandemic remote-learning environment, and it could be replicated in other pharmacy or healthcare programmes to enrich students' active learning in virtual education.
\end{abstract}

\section{Introduction}

Circumstances in the current learning environment have accelerated the use, adoption and integration of technology for virtual collaboration into learning modalities of pharmacy programmes. For example, the absence of affiliated academic medical centres for many colleges/schools of pharmacy has challenged interprofessional education (IPE) initiatives requiring medical students (Williams et al., 2019); therefore, in some instances, remote collaboration between colleges/schools of pharmacy and medicine utilising technology has become a necessity. In addition, globalisation and the need to develop cultural sensitivity have also been associated with increasing use of technology in education (Cabatan \& Grajo, 2017; Duncan et al., 2018; Honey, Young, \& Cowls, 2019; Wihlborg et al., 2018). In this instance, technology is similarly instrumental to facilitate collaboration between students in different countries and/ or geographic divides. Following the declaration of the COVID-19 Pandemic by the World Health Organization (WHO) on $11^{\text {th }}$ March 2020, many educational institutions 
had to make a swift conversion to virtual distance learning. They subsequently found immediate challenges and barriers to implementing traditional teaching and assessment strategies, whilst sustaining active student engagement, in a remote learning environment. Therefore, it is crucial to conduct studies that assess the impact and sustainability of virtual educational strategies on student performance, both in the short term (i.e., 2020-2021) and the long term.

Of necessity for remote education, faculty often modify traditional teaching, learning and assessment activities, and they also invent new models to deliver content and evaluate learning virtually. Fortuitously, readily available technology has provided opportunities to integrate active learning strategies such as debate or mock trials. Such methods for student-interaction maintain student engagement while simultaneously enhancing critical thinking, collaboration, and public speaking skills (Sumida Garcia \& Costa Silva, 2017). Challenges related to technology and physical barriers are not unexpected with a transition to an all-virtual education. While specific technology may not be new, the manner of adequate technology operation may be unfamiliar to students and can influence whether a learning activity achieves its intended goals. For example, synchronous virtual sessions may be diverted from the original task to resolve technology issues (Vuopala et al., 2016). Additionally, during student-participation in virtual active learning activities, discussions may lean toward group-dynamics rather than task-related issues (Vuopala, Hyvönen, \& Järvelä, 2016). During the course of virtual learning, students also form perceptions of the specific technology such as ease of use and perceived usefulness, which was found to directly and indirectly influence students' future intentions regarding using the technology (Wang, Anne, \& Ropp, 2016).

\section{Use of a Mock Trial in Healthcare Education}

A mock trial is a teaching-assessment strategy implemented in a classroom setting where students simulate an actual trial and debate controversial topics before a panel of judges/jurors. Mock trials foster active learning while also enhancing critical-thinking and communication skills (Ahmadov, 2011). Often employed in legal (Kravetz, 2001) and political science education (Bengtson \& Sifferd, 2010), mock trials have been adopted in other educational contexts such as medicine (Gilber et al., 2003), nursing (March et al., 2011; Troxel, 2012), and physical therapy (Heiss \& Basso, 2003). A pharmacy programme on the West Coast of the United States (Programme B) implemented a mock trial project, subsequently expanding the project to include a second pharmacy programme on the East Coast (Programme A) (Rosenberg et al., 2018). To the authors knowledge, mock trials in pharmacy education have not previously been implemented virtually.

In mid-March 2020, both Programmes A and B transitioned to an all-virtual course delivery in response to the COVID-19 pandemic. Whereas the mock trial historically was held in-person every spring, such a sudden change sparked the notion that mock trials in spring 2020 could continue by being delivered virtually via video conferencing technology. Reflecting on a pilot-test of a mock trial competition between the two programmes via video conferencing technology the year before, it seemed reasonable and achievable to similarly conduct each programme's respective 2020 mock trials virtually. To date, few studies have evaluated active learning in context of virtual distance learning within pharmacy education. Given that mock trial activities provide a teachingassessment strategy that focuses on active learning, this study aims to contribute to the literature by evaluating the feasibility of a Virtual Mock Trial (VMT) which was adopted primarily in response to the COVID-19 pandemic.

\section{Objectives}

The purpose of the study was to evaluate the feasibility of a Virtual Mock Trial (VMT) by examining:

- faculty-judges' and student-jurors' respective assessments of students' performance outcomes in the VMT

- students' perceptions about the use of technology and how technology facilitates student-participation in the VMT, and

- the overall process and experience

\section{Methods}

The Mock Trial Project (MTP), a previously validated teaching-assessment process (Rosenberg et al., 2018) was implemented in 2020 as a Virtual Mock Trial (VMT) in response to the COVID-19 pandemic. During the VMTs, pharmacy students debated controversial issues in healthcare, pharmacy practice and/or pharmacotherapy in a courtroom style format. Throughout the semester, student-teams researched assigned trial topics, identified best evidence to develop trial arguments supporting their respective positions, and debated in a mock trial (Rosenberg et al., 2018). Following the stay-at-home orders, the mock trials took place virtually on $13^{\text {th }}$ April 
2020 for Programme A, and on 20th April 2020 for Programme B. As in the previous MTP, the VMT was the final exam (Rosenberg et al., 2018). During the VMT, student-teams argued their positions using video conferencing technology from their stay-at-home locations. A panel of faculty-judges and student-jurors in each trial used the same technology to observe and evaluate each team's performance. Scores from facultyjudges, student-jurors, and peer-evaluators determined the students' grades.

The video conferencing technology used for the VMT, Blackboard Collaborate, was available for both programmes. Blackboard Collaborate enables face-to-face conversation, document sharing for real-time exhibits, and live entry of comments and questions. Students had become familiar with the Blackboard Collaborate features from previous experiences; thus, no specific adaptations of the Blackboard Collaborate were needed. At the scheduled time, all students logged into Blackboard Collaborate from their stay-at-home locations. Due to the different cohort sizes at each programme, Programme A completed two VMT sessions, and Programme B carried out three sessions. Each VMT session featured a unique trial topic, such as using antimicrobials in livestock, directto-consumer prescription drug advertising, and making oral contraceptives available over the counter.

Trial procedure for the VMT replicated the previously described trial procedure in the classroom with no modification (Figure 1) (Rosenberg et al., 2018). Students' trial roles included (for each side, Petitioner and Respondent):

I. counsel to deliver an opening statement (two per trial);

II. counsel to deliver closing arguments (two per trial);

III. counsel to conduct direct and cross examination of each witness (two per witness).

Three witnesses testified for each side; the decision to use experts or lay witnesses was left to students on trialteams. Student-teams also strategised whether an actual expert would testify in the respective witness-roles, or alternatively, whether a student on the team would roleplay the part of an expert or lay witness. Student-jurors for each trial were selected from those students participating in the other trial-sessions. The number of jurors ranged from nine to 12 per trial depending on the cohort size. Students with speaking roles (counsel or witness) at VMT each had four minutes to speak; student-jurors each had one minute to present their individual opinions before the jury panel voted on a verdict. Each trial took about 1.5 hours from the start of the petitioner's opening statement to the jury's verdict.

To ensure smooth implementation of VMT, faculty delivered clear steps and instructions to facilitate effortless transition from one student-speaker to another. Each team designated a member to assist with PowerPoint exhibits and to remind consecutive speakers to be ready. This approach ensured that student-speakers (e.g. counsel on direct or cross exam of witness) could focus on the content and not be distracted by technology.

Assessment of students' perceptions on the technology used to facilitate the VMT relied on a survey instrument, which was developed based on the Technology Acceptance Model (TAM), a theoretical framework that illustrates various constructs related to individual behavioural intention with respect to use of a technology (Davis, 1989). Figure 2 illustrates the four categories within TAM and their associations with each other. Twenty specific statements were adapted from existing literature evaluating technology use in educational settings (Alharbi \& Drew, 2014; Ronnie, Christopher, \& Eugenia, 2011) and included in the final survey; the first 16 items were developed to assess the four categories in the TAM framework: 'perceived usefulness' (Items 1-5), 'perceived ease of use' (Items 6-10), 'attitude towards using' (Items 11-14), and 'behavioural intention to use' (Items 15 and 16). The Cronbach's alpha for each category was found to be above 0.9 , indicating great internal consistency in each category. The last four items in the survey (Items 17-20) inquired about students' perceptions of the VMT experience. Students were asked to indicate their level of agreement using a 7-point Likert scale ( 1 = strongly disagree; 7 = strongly agree). A similar student perception survey focusing on different technology use in the MTP was administered in the previous year, and no major issues with the survey questions or administration were reported. The survey was administered electronically via Google Forms; student participation was voluntary. All student-participants received an email providing a link to the survey immediately after the VMT, followed by a reminder. Students had approximately two weeks to complete the survey.

The panels of faculty-judges and student-jurors evaluated student performance in the VMTs. Three faculty members at Programme A and five at Programme B served as the judges; the same set of faculty-judges evaluated all trials in their respective programme. As to the credentials of faculty-judges, one faculty has a law degree (i.e., JD); one faculty is the director of assessment within the school of pharmacy; and several other faculty members had served 
Figure 1: Role Schematic and Trial Procedure in 2020 Virtual Mock Trial (VMT)

Schematic for Virtual Mock Trial (VMT): TEAM A TRIAL

Example Topic: 'Whether or not use of antibiotics in livestock should be permitted?'

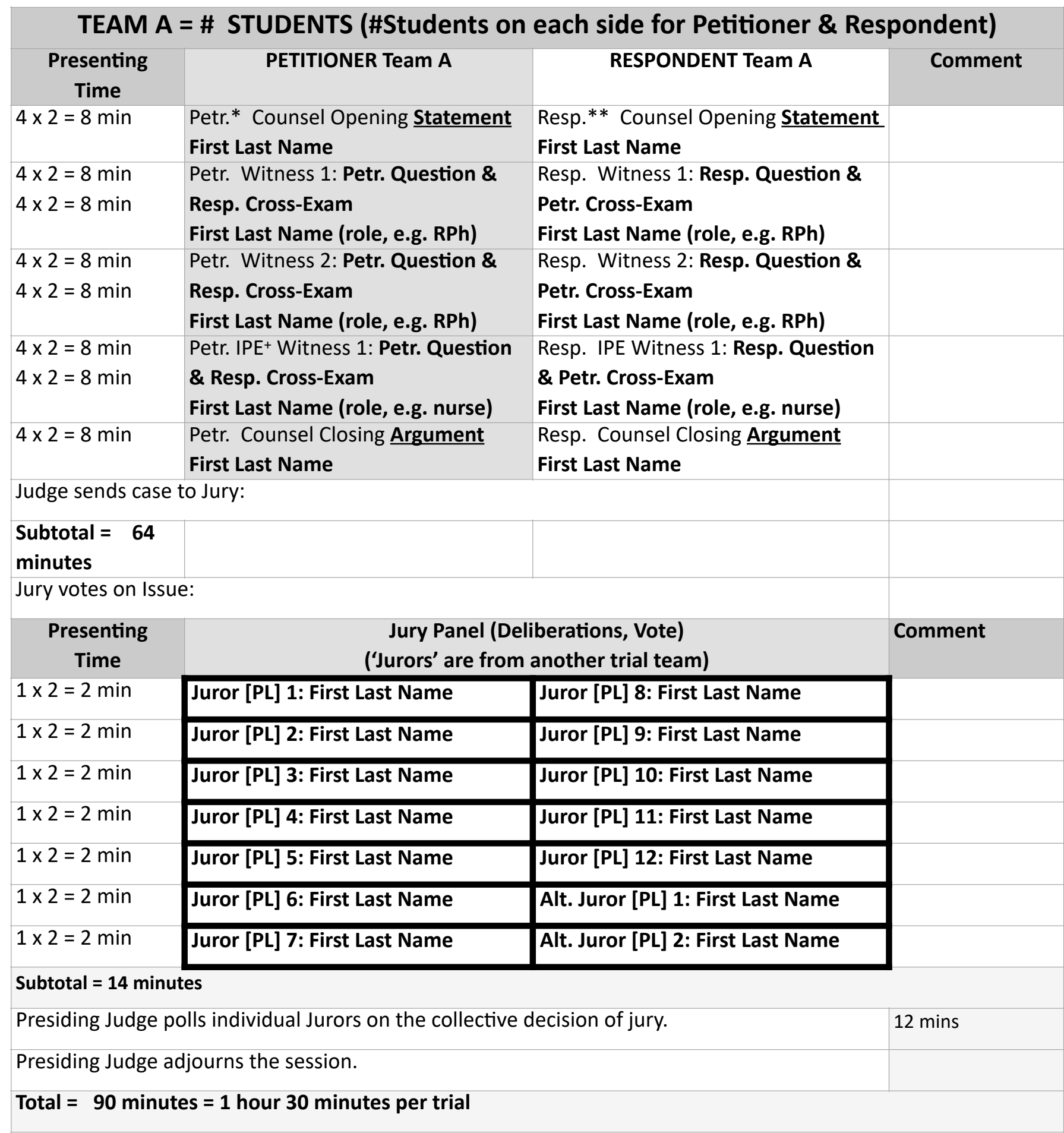

Petr.* : Petitioner

Resp. **: Respondent

$\mathrm{IPE}^{+}$: Interprofessional Education 


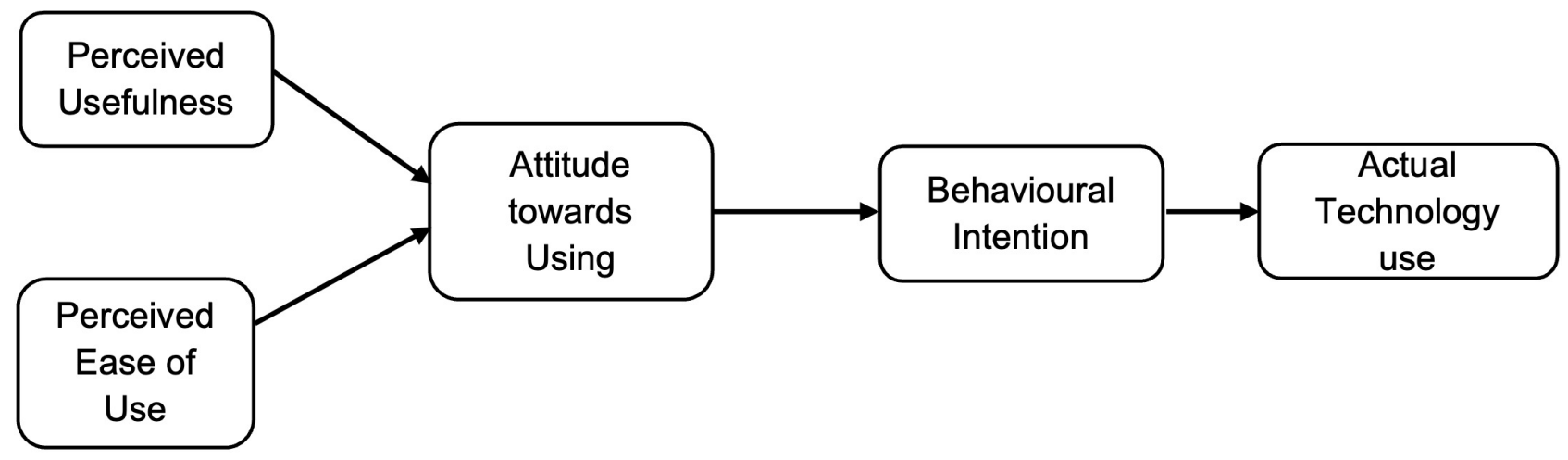

Figure 2: Technology Acceptance Model (TAM)

as the faculty-judges for the mock trials in the past. The number of student-jurors varied slightly in each VMT; 11-12 students served as the jurors at Programme $A$, whereas 9-10 students served as the jurors at Programme B. Faculty-judges and student-jurors assessed students using previously-established rubrics (Appendix B) (Rosenberg et al., 2018). Criteria included cognitive and affective domain areas: content/knowledge; critical thinking; application/discussion of federal/state law; literature citations/references; visual aids; delivery/style; and active listening (Rosenberg et al., 2018). The panels of faculty-judges and student-jurors assessed students during VMT sessions and submitted their evaluations via Google Forms.

Average scores for each student-team provided by the faculty-judges and student-jurors were calculated and presented as a percentage. Descriptive analyses were performed on survey responses. Mean and standard deviations were computed for the four TAM categories and the four general assessment questions. Based on the distribution of survey scores, nonparametric tests (i.e., Wilcoxon-Mann-Whitney test) were conducted to compare the results between the programmes; $p$ values less than 0.05 were considered statistically significant. Statistical analyses were conducted using the SAS University Edition. This study received approval from the Institutional Review Board (IRB) at WCU in April 2018 and at UMES in June 2018.

\section{Results}

First professional-year (P1) students (Programme A: 46.0; Programme B: 89.0$)$ participated in the VMTs. The panels of faculty-judges for each trial rated the respective VMT performance for all student groups $\geq 85.0 \%$ or above, irrespective of the programme or trial-topic (Table I). Overall, the faculty-judges' evaluation scores ranged from
85.0\% to 96.7\% (Programme A: 85.0-88.3\%; Programme B: 91.3-96.7\%.). Student-jurors also rated VMT performances $\geq 85.0 \%$ for most student groups with two exceptions. The Trial I Respondent group and Trial II Petitioner group at Programme A received performance scores of $71.8 \%$ and $68.3 \%$ respectively. The student-jurors' evaluation scores overall ranged from $68.3 \%$ to $100 \%$ (Programme A: 68.3-91.8\%; Programme B: 93.0-100\%). In comparing student performance scores between the two programmes, both faculty-judges and student-jurors generally gave higher ratings to the students at Programme $B$ (Table I). A possible explanation for this could be that facultyjudges and student-jurors of Programme $A$ applied and interpreted the evaluation criteria more closely, thus having evaluations that are 'more stringent' than those in Programme B.

Table I: Evaluation of Student Performance in the Virtual Mock Trial by Faculty-Judges and Student-Jurors

\begin{tabular}{|c|c|c|c|c|c|}
\hline & & \multicolumn{2}{|c|}{$\begin{array}{l}\text { Average Judge } \\
\text { Evaluation (\%) }\end{array}$} & \multicolumn{2}{|c|}{$\begin{array}{c}\text { Average Juror Evaluation } \\
(\%)\end{array}$} \\
\hline & & $\begin{array}{c}\text { Programme } \\
\text { A }(\mathbf{n}=\mathbf{3})\end{array}$ & $\begin{array}{c}\text { Programme } \\
\text { B }(n=5)\end{array}$ & $\begin{array}{l}\text { Programme } \\
\text { A }\left(n=12^{\sim 13}\right)\end{array}$ & $\begin{array}{l}\text { Programme } \\
B(n=9 \sim 11)\end{array}$ \\
\hline \multirow[t]{2}{*}{$\begin{array}{l}\text { Trial } \\
\text { I }\end{array}$} & Petitioners & 86.3 & 92.0 & 89.3 & 94.3 \\
\hline & Respondents & 88.3 & 93.3 & 71.8 & 99.3 \\
\hline \multirow[t]{2}{*}{$\begin{array}{l}\text { Trial } \\
\text { II }\end{array}$} & Petitioners & 85.0 & 95.3 & 68.3 & 99.7 \\
\hline & Respondents & 88.3 & 96.7 & 91.8 & 100 \\
\hline \multirow[t]{2}{*}{$\begin{array}{l}\text { Trial } \\
\text { III }\end{array}$} & Petitioners & $N A^{*}$ & 91.3 & NA & 93.3 \\
\hline & Respondents & NA & 93.0 & NA & 93.0 \\
\hline
\end{tabular}

*NA: Not Applicable

Forty-three student-participants at Programme A and 82 at Programme B completed the post-VMT survey, yielding a combined response rate of $92.6 \%$. Each TAM category (i.e. Perceived Usefulness, Perceived Ease of Use, Attitude 
towards using, and Behavioural Intention) reported means $>5$ on a 7-Point Likert Scale (Table II). 'Perceived Ease of Use' had the highest average (Table II: Programme A : 5.93; Programme B : 6.35), and 'Behavioural Intention' received the lowest average ratings (Programme $A$ : 5.51 ; Programme B : 6.12). Average ratings provided by students at Programme B were higher than those provided by Programme A students in every TAM category. Specifically, ratings for 'Perceived Ease of Use' and 'Behavioural Intention' were significantly different between two programmes $(p<0.05)$.

The majority of the students provided a rating of 6 or 7 on a 7-Point Likert Scale for each of the following four items:

(1) I am satisfied with the general process and experience of participating in the virtual mock trial ( $\mathrm{n}$ $=99,79.2 \%)$,

(2) The mock trial project itself enhanced my critical thinking skills such as those used in evidence-based decision making ( $n=103,82.4 \%$ ),

(3) My participation in the mock trial project enabled me to debate on the pros and cons of a controversial issue in healthcare $(n=103,82.4 \%)$, and

(4) I would recommend the mock trial project to other students as a valuable learning activity $(n=100$, $80.0 \%)$.
Table II: Comparison of the technology acceptance model subscale scores between two schools

\begin{tabular}{|c|c|c|c|c|c|c|c|c|c|}
\hline & \multicolumn{4}{|c|}{ Programme A ( $n=43)$} & \multicolumn{4}{|c|}{ Programme B $(n=82)$} & \multirow{2}{*}{$p^{+}$} \\
\hline & Mean & $\mathrm{SD}^{++}$ & Max* & Min** & Mean & SD & Max & Min & \\
\hline $\begin{array}{l}\text { Perceived } \\
\text { Usefulness }\end{array}$ & 5.91 & 1.28 & 7.00 & 2.60 & 6.31 & 1.01 & 7.00 & 2.00 & $>0.05$ \\
\hline $\begin{array}{l}\text { Perceived } \\
\text { Ease of Use } \\
\text { Attitude }\end{array}$ & 5.93 & 1.07 & 7.00 & 3.00 & 6.35 & 0.94 & 7.00 & 3.40 & 0.02 \\
\hline $\begin{array}{l}\text { Towards } \\
\text { Using }\end{array}$ & 5.82 & 1.31 & 7.00 & 2.25 & 6.18 & 1.23 & 7.00 & 1.25 & $>0.05$ \\
\hline $\begin{array}{l}\text { Behavioural } \\
\text { Intention }\end{array}$ & 5.51 & 1.57 & 7.00 & 1.50 & 6.12 & 1.35 & 7.00 & 1.00 & 0.01 \\
\hline
\end{tabular}

$p^{+}$-value obtained from performing nonparametric tests

$\mathrm{SD}^{++}$: Standard deviation

Max*: Maximum value

Min**: Minimum value

On the other hand, four students (3.2\%) rated 3 or lower on the item seeking student satisfaction about VMT, and nine students (7.2\%) on the item about recommending the mock trial project to other students. Seven students (5.6\%) rated 3 or lower on the two items asking whether the MTP enhances critical thinking skills and enables debate of controversial issues. The average rating on student satisfaction with VMT experience was higher among Programme B students (Table III: Programme A : 5.79, Programme B : 6.45; $p=0.002$ ). Programme B students also reported a higher average score on willingness to recommend VMT activity. (Table III: Programme A : 5.88, Programme B : 6.29; $p=0.026$ ).

Table III: Student Perceptions toward the Overall Experience in Virtual Mock Trial

\begin{tabular}{|c|c|c|c|c|c|c|c|c|c|}
\hline \multirow[b]{2}{*}{ Survey Item } & \multicolumn{4}{|c|}{ Programme A (n= 43) } & \multicolumn{4}{|c|}{ Programme B (n= 82) } & \multirow[t]{2}{*}{$\boldsymbol{p}^{* * *}$} \\
\hline & Mean+ & SD* & Max** & Min++ & Mean & SD & Max & Min & \\
\hline $\begin{array}{l}\text { I am satisfied with the general process and experience } \\
\text { of participating in the virtual mock trial. }\end{array}$ & 5.79 & 1.37 & 7.00 & 2.00 & 6.45 & 0.96 & 7.00 & 3.00 & 0.002 \\
\hline $\begin{array}{l}\text { The mock trial project itself enhanced my critical } \\
\text { thinking skills such as those used in evidence-based } \\
\text { decision making. }\end{array}$ & 5.81 & 1.52 & 7.00 & 2.00 & 6.45 & 1.02 & 7.00 & 2.00 & 0.015 \\
\hline $\begin{array}{l}\text { The mock trial project enabled me to debate on the } \\
\text { pros and cons of a controversial issue in healthcare. }\end{array}$ & 5.93 & 1.52 & 7.00 & 2.00 & 6.51 & 0.98 & 7.00 & 3.00 & 0.025 \\
\hline $\begin{array}{l}\text { I would recommend the mock trial project to other } \\
\text { students as a valuable learning activity. }\end{array}$ & 5.88 & 1.45 & 7.00 & 2.00 & 6.29 & 1.37 & 7.00 & 1.00 & 0.026 \\
\hline
\end{tabular}

\footnotetext{
+ Responses were measured using a 7-point Likert scale 1 = strongly disagree; 7 = strongly agree

SD*: Standard deviation

Max**: Maximum value

$\mathrm{Min}^{++}:$Minimum value

$p^{* * *}: P$-value obtained from nonparametric tests
} 


\section{Discussion}

Based on the consistent success of student-participants in the two physically distanced pharmacy programmes, it is reasonable to state that the VMT is feasible given students' different locations. Students' performance outcomes were rated positively by the faculty-judges and student-jurors. Feedback from the student-perception survey indicated that students perceived the video conferencing technology as useful and easy to use for the purpose of facilitating participation in VMTs. Students expressed a positive attitude and a strong behavioural intention toward using the technology in the future, which suggests that the teaching-assessment strategy facilitated by the technology is well-received. Interestingly, Programme B students expressed consistently higher ratings on average than Programme A students with regard to technology use and overall VMT and mock trial experience.

It is important to note that the implementation process and timeline required faculty decisiveness in transitioning to VMT. Both programmes rapidly converted all in-person instruction into virtual-only instruction due to the pandemic. With little lead time, the planning and execution of the VMT were completed within a month. Programme A implemented its VMT on the $13^{\text {th }}$ April, 2020, and Programme B implemented its VMT on the $20^{\text {th }}$ April, 2020. The bicoastal collaboration of two programmes added yet another dimension and level of complexity to the VMT. However, strong collaborative relationships between faculty at the two programmes facilitated a swift and smooth transition and ensured overall consistency in the parallel implementation of different VMT sessions.

Both faculty and students made the transition and adjustments to VMTs in a very short time frame. Notably, this transition occurred without the assistance of staff and access to information technology (IT) support, because other courses in the two programmes also suddenly changed to online delivery making pandemic-related demands on those supportive resources. Therefore, a recommendation for future VMTs is to incorporate IT support to enhance students' experiences. Nonetheless, the VMT was implemented smoothly following the process that the authors laid out in advance (Rosenberg et al., 2018). This is due to the continuing collaborative relationship among faculty from both programmes and the extensive prior experience of implementing mock trials for four years. Also, by the time of the VMT, students had been using Blackboard Collaborate for over a month for distance learning. The students' prior experiences may be associated with students' ability to successfully navigate the technology during VMT.

Implementation of the VMT was generally seamless, yet not without challenges. On the day of the VMT at Programme A, a storm impacted Wi-Fi connectivity for some students. Due to its location in a rural area, broadband internet access was not readily available. As a result, many students connected to the internet services via cell phone hotspots, which also was subject to service interruption by the same weather condition. When unanticipated and unstable Wi-Fi connectivity issues occurred, some students and faculty waited for reconnection, while others reported to dial-in via phone only without video-sharing capability. Other than the weather challenge, several students commented in the survey that they would prefer to have an opportunity to practice 'sharing their screen' and test their audio prior to the actual VMT session. Doing so would facilitate a better transition from one presenter to another during the VMTs.

Virtual and collaborative learning experiences are reported to provide opportunities for students to practice and demonstrate their intercultural competency skills (Olivos Rossini, Rincón, \& Rutkowski, 2015). Olivos Rossini and colleagues (2015) found students from different countries varied in their expectations about ease of use regarding the technology and how well emotions could be conveyed virtually (Olivos Rossini, Rincón, \& Rutkowski, 2015). Similarly, this current study found that Programme $B$ students reported higher average ratings for 'technology use' and 'overall VMT experience' than those from Programme A. The differences in students' ratings across two programmes could reflect either unique factors in play, or challenges that both programmes encountered during the VMT. Reflecting on the VMT process and timeline, it is also noteworthy that Programme $A$ implemented the VMT one week prior to Programme B, which gave faculty at Programme $B$ an opportunity to observe the implementation of VMT at Programme A and to incorporate lessons learned into the VMT at Programme B one week later. For example, at Programme A, when a student spoke during their role as the counsel or witness, another student shared their own screen to show and advance exhibits on slides. This studentpartnership was implemented to avoid distraction for students executing a speaking role in the VMT. Shortly thereafter at Programme B, one designated student in each trial-session shared their screen for the entire duration of the VMT, which is an example of adopting lessons learned from the VMT held at another school in the prior week. 
There were several limitations in the study. First, evaluations of VMT process and mock trial project were obtained solely from students who participated in the trial. Faculty-judges who observed the VMT process could also have provided valuable feedback and recommendations for improvement. Thus, faculty-judges should be surveyed for this purpose in the future. Second, one programme reported consistently higher ratings from both faculty and students, suggesting potential grade inflation. It would be helpful to provide training to the VMT evaluators, including both faculty-judges and studentjurors to ensure consistency in the application of the evaluation criteria. There was also a noted difference in the number of faculty involved in the VMT planning and in the level of prior experience of faculty-judges evaluating student performance. Programme A had three judges, including one new first-year faculty; Programme $B$ had five judges all with some level of prior experience in evaluating mock trials. Providing training for faculty and student evaluators can help to ensure internal validity and interrater reliability.

Despite limitations, several factors suggest that VMT can be replicated at other pharmacy programmes. First, the fact that VMT was implemented concurrently at the two pharmacy programmes, each with very distinct characteristics, provides preliminary evidence that VMT is not limited to a particular type of programme or geographical setting. While both programmes can be considered academically and geographically multicultural, the institutional profiles of the two pharmacy programmes differ in several regards. For instance, Programme $A$ is a public institution located in a rural area on the East Coast of the United States, while Programme B is a private institution in a major metropolitan area on the West Coast. The compositions of the respective student bodies at the two programmes also vary. Second, programme length and therefore curricula differ between the two programmes (Programme A: three-year accelerated; Programme B: four-year traditional), yet both programmes successfully implemented the VMT in a required course during the spring semester of the P1 year. Last, neither programme had staff and IT support for the VMT, indicating that there may be no necessity for additional resources to implement VMT.

Technology is usually a key determining factor in the adoption of a new teaching-assessment strategy into distance learning. In this case, faculty spent time reinforcing their understanding of Blackboard Collaborate features and developing best approaches to facilitate VMT. Fortunately, students quickly adapted to the technology and VMT process. Since VMT can be implemented without concerns for geographic barriers, a plausible future direction would be to expand the VMT to pharmacy programmes in other regions, or countries. For both programmes, specific future plans include having two standalone VMTs and potentially a competition between two programmes. Another potential next step is to engage additional faculty from other health professions to facilitate interprofessional collaboration.

\section{Conclusion}

Overall, it is reasonable to conclude that VMTs were successfully implemented at two United States of America pharmacy programmes. The present study demonstrated that faculty-judges and student-jurors assessed students' performance outcomes of VMT positively; students perceived the video conferencing technology as useful and easy to use for the purpose of facilitating participation in VMT; students expressed a positive assessment of the overall VMT experience and would recommend this learning activity to other students. Therefore, VMT can be considered as a feasible virtual teaching-assessment strategy in the current pandemic and beyond. Given the distinct organisational characteristics between the two programmes, there is evidence suggesting that VMTs can also be replicated by other pharmacy and health professional programmes to enhance students' active engagement and enrich their virtual educational experiences.

\section{References}

Ahmadov, A. (2011). When great minds don't think alike: Using mock trials in teaching political thought. PS: Political Science and Politics, 44(3), 625-628. https://doi.org/10.1017/ S1049096511000722

Alharbi, S., \& Drew, S. (2014). sing the Technology Acceptance Model in Understanding Academics' Behavioural Intention to Use Learning Management Systems. International Journal of Advanced Computer Science and Applications (IJACSA), 5(1). https://doi.org/10.14569/IJACSA.2014.050120

Bengtson, T.J., \& Sifferd, K.L. (2010). The unique challenges posed by mock trial: Evaluation and assessment of a simulation course. Journal of Political Science Education, 6(1), 70-86. https:// doi.org/10.1080/15512160903467638

Cabatan, M.C.C., \& Grajo, L.C. (2017). Internationalization in an Occupational Therapy Curriculum: A Philippine-American Pilot 
Collaboration. The American Journal of Occupational Therapy, 71(6), https://doi.org/10.5014/ajot.2017.024653

Davis, F.D. (1989). Perceived usefulness, perceived ease of use, and user acceptance of information technology. MIS Quarterly: Management Information Systems, 13(3), 319-340. https:// doi.org/10.2307/249008

Duncan, F.E., Romar, R., Gadea, J., Kimelman, D., Wallach, H.D., Woodruff, T.K., \& Jiménez-Movilla, M. (2018). The use of a virtual journal club to promote cross-cultural learning in the reproductive sciences. Journal of Assisted Reproduction and Genetics, 35(12), 2141-2147. https://doi.org/10.1007/ s10815-018-1309-z

Gilbert, W.M., Fadjo, D.E., Bills, D.J., Morrison, F.K., \& Sherman, M.P. (2003). Teaching malpractice litigation in a mock trial setting: A center for perinatal medicine and law. Obstetrics and Gynecology, 101(3), 589-593. https://doi.org/10.1016/ S0029-7844(02)03133-2

Heiss, D.G., \& Basso, D.M. (2003). Physical therapy on trial: The rationale, organization, and impact of a mock trial on physical therapy students' attitudes toward and confidence in research. Journal of Allied Health, 32(3), 202-210.

Honey, M., Young, K., \& Cowls, H. (2019). Virtual Student Collaboration: Connecting Student Health Professionals. Studies in health technology and informatics, 264, 1935-1936. doi: 10.3233/SHTI190721

Kravetz, K. (2001). The mock trial course in justice education. International Journal of Phytoremediation, 12(1), 147-168. https://doi.org/10.1080/10511250100085101

March, A.L., Ford, C.D., Adams, M.H., Cheshire, M., \& Collins, A. S. (2011). The mock trial: A collaborative interdisciplinary approach to understanding legal and ethical issues. Nurse Educator, 36(2), 66-69. https://doi.org/10.1097/NNE. Ob013e31820b5029

Olivos Rossini, M., Rincón, S., \& Rutkowski, A.F. (2015). The Link Class Project: Collaborative virtual teams between Peru and The Netherlands. Journal of Economics, Finance and Administrative Science, 20(39), 137-140. https://doi.org/10.1016/j.jefas. 2015.10.001

Ronnie, H.S., Christopher, C.D., \& Eugenia, M.W.N. (2011). Analysis of the technology acceptance model in examining students' behavioural intention to use an e-portfolio system. Australasian Journal of Educational Technology, 27(4). https:// doi.org/10.14742/ajet.940

Rosenberg, E., Truong, H.A., Hsu, S.Y., \& Taheri, R. (2018). Implementation and lessons learned from a mock trial as a teaching-learning and assessment activity. Currents in Pharmacy Teaching and Learning, 10(8), 1076-1086. https://doi.org/ 10.1016/j.cptl.2018.05.014
Sumida Garcia, L., \& Costa Silva, C.M. (2017). Differences between perceived usefulness of social media and institutional channels by undergraduate students. Interactive Technology and Smart Education, 14(3), 196-215. https://doi.org/10.1108/ ITSE-01-2017-0009

Troxel, D. (2012). Staging a Mock Trial: Educating Nurses on the Importance of Documenting Critical Values. Nursing for Women's Health, 16(3), 243-246. https://doi.org/10.1111/j.1751-486X. 2012.01736.x

Vuopala, E., Hyvönen, P., \& Järvelä, S. (2016). Interaction forms in successful collaborative learning in virtual learning environments. Active Learning in Higher Education, 17(1), 25-38. https:// doi.org/10.1177/1469787415616730

Wang, Y., Anne, A., \& Ropp, T. (2016). Applying the technology acceptance model to understand aviation students' perceptions toward augmented reality maintenance training instruction. International Journal of Aviation, Aeronautics, and Aerospace, 3(4). https://doi.org/10.15394/ijaaa.2016.1144

Wihlborg, M., Friberg, E.E., Rose, K.M., \& Eastham, L. (2018). Facilitating learning through an international virtual collaborative practice: A case study. Nurse Education Today, 61, 3-8. https:// doi.org/10.1016/j.nedt.2017.10.007

Williams, J.S., Spivey, C.A., Hagemann, T.M., Phelps, S.J., \& Chisholm-Burns, M. (2019). Impact of Pharmacy School Characteristics on NAPLEX First-time Pass Rates. American Journal of Pharmaceutical Education, 83(6), 1366-1372. https:// doi.org10.5688/ajpe6875 


\section{Appendix}

\section{Appendix A: Post-VMT Survey}

2020 Technology Acceptance Model (TAM) Survey for Video Conferencing Technology - Student evaluation of video conferencing technology used for virtual mock trial

\begin{tabular}{|c|c|c|c|c|c|c|}
\hline \multirow[b]{3}{*}{ 1. Using the video conferencing technology ENABLED ME TO PARTICIPATE in the virtual mock trial. } & \multirow{2}{*}{\multicolumn{2}{|c|}{$\begin{array}{l}\text { Strongly } \\
\text { DISAGREE }\end{array}$}} & \multirow{3}{*}{\multicolumn{4}{|c|}{$\begin{array}{c}\text { Strongly } \\
\text { AGREE } \\
7\end{array}$}} \\
\hline & & & & & & \\
\hline & 1 & 3 & & & & \\
\hline $\begin{array}{l}\text { 2. Using the video conferencing technology ENHANCED EFFECTIVENESS of MY COMMUNICATION } \\
\text { in the virtual mock trial. }\end{array}$ & 1 & 3 & 4 & 5 & 6 & 7 \\
\hline 3. Using the video conferencing technology MADE IT EASIER to engage in the virtual mock trial. & 1 & 3 & 4 & 5 & 6 & 7 \\
\hline $\begin{array}{l}\text { 4. I believe the video conferencing technology is USEFUL for STUDENT PARTICIPATION in a virtual } \\
\text { mock trial. }\end{array}$ & 1 & 3 & 4 & 5 & 6 & 7 \\
\hline $\begin{array}{l}5 . \text { I believe that the video conferencing technology is also USEFUL for OTHER virtual student group } \\
\text { presentations. }\end{array}$ & 1 & 3 & 4 & 5 & 6 & 7 \\
\hline $\begin{array}{l}\text { 6. Overall, I found the video conferencing technology EASY TO USE based on my experience in the } \\
\text { virtual mock trial. }\end{array}$ & 1 & 3 & 4 & 5 & 6 & 7 \\
\hline 7. My INTERACTIONS with the video conferencing technology were CLEAR and UNDERSTANDABLE. & 1 & 3 & 4 & 5 & 6 & 7 \\
\hline 8. I believe the video conferencing technology is FLEXIBLE TO INTERACT WITH. & 1 & 3 & 4 & 5 & 6 & 7 \\
\hline 9. LEARNING to OPERATE the video conferencing technology would be EASY for ME. & 2 & 3 & 4 & 5 & 6 & 7 \\
\hline $\begin{array}{l}\text { 10. I believe that it would be EASY in general for MOST STUDENTS to BECOME SKILLED at using } \\
\text { video conferencing technology for a virtual mock trial. }\end{array}$ & 1 & 3 & 4 & 5 & 6 & 7 \\
\hline $\begin{array}{l}\text { 11. I have a GENERALLY FAVORABLE ATTITUDE toward using the video conferencing technology for } \\
\text { a virtual mock trial. }\end{array}$ & 1 & 3 & 4 & 5 & 6 & 7 \\
\hline 12. I believe it is a GOOD IDEA to use video conferencing technology for the virtual mock trial. & 1 & 3 & 4 & 5 & 6 & 7 \\
\hline 13. I LIKE the IDEA of using video conferencing technology for the virtual mock trial. & 1 & 3 & 4 & 5 & 6 & 7 \\
\hline $\begin{array}{l}\text { 14. I believe that using video conferencing technology was GENERALLY HELPFUL for me in the } \\
\text { virtual mock trial. }\end{array}$ & 1 & 3 & 4 & 5 & 6 & 7 \\
\hline $\begin{array}{l}\text { 15. I RECOMMEND using video conferencing technology for other virtual student group } \\
\text { presentations in the future. }\end{array}$ & 1 & 3 & 4 & 5 & 6 & 7 \\
\hline $\begin{array}{l}\text { 16. I INTEND (PLAN) to use video conferencing technology as often as possible for other virtual } \\
\text { student group presentations. }\end{array}$ & 1 & 3 & 4 & 5 & 6 & 7 \\
\hline $\begin{array}{l}\text { 17. I am SATISFIED with the GENERAL PROCESS and EXPERIENCE of participating in the virtual } \\
\text { mock trial. }\end{array}$ & 1 & 3 & 4 & 5 & 6 & 7 \\
\hline $\begin{array}{l}\text { 18. The mock trial project itself ENHANCED MY CRITICAL THINKING SKILLS such as those used in } \\
\text { evidence-based decision making. }\end{array}$ & 1 & 3 & 4 & 5 & 6 & 7 \\
\hline $\begin{array}{l}\text { 19. My participation in the mock trial project ENABLED me to debate on the pros and cons of a } \\
\text { controversial issue in healthcare. }\end{array}$ & 1 & 3 & 4 & 5 & 6 & 7 \\
\hline $\begin{array}{l}\text { 20. I would recommend the mock trial project to OTHER STUDENTS as a VALUABLE learning } \\
\text { activity. }\end{array}$ & 12 & 3 & 4 & 5 & 6 & 7 \\
\hline What is your school of pharmacy? & UMES & & & CU & & \\
\hline $\begin{array}{l}\text { What comments do you have about the MOCK TRIAL PROJECT / EXPERIENCE? When appropriate, } \\
\text { please indicate the number of question (\# above) that you are referring to. }\end{array}$ & & & & & & \\
\hline $\begin{array}{l}\text { What comments do you have about the video conferencing technology? When appropriate, } \\
\text { please indicate the number of question (\# above) that you are referring to. }\end{array}$ & & & & & & \\
\hline
\end{tabular}


Appendix B: Faculty-Judge and Student-Juror Evaluation Form 2020 Mock Trial JUDGE/JUROR Evaluation Form

Petitioner: What evidence-based arguments SUPPORT_ (Trial Topic) ?

Respondent: What evidence-based arguments caution AGAINST_ (Trial Topic) ?

\begin{tabular}{|c|c|c|c|c|c|c|}
\hline Evidence & $\begin{array}{l}\text { Strong Evidence } \\
\text { (3.0 points) }\end{array}$ & $\begin{array}{l}\text { Good Evidence } \\
\text { (2.5 points) }\end{array}$ & $\begin{array}{l}\text { Some Evidence } \\
\text { (1.5 points) }\end{array}$ & $\begin{array}{l}\text { Little } \\
\text { Evidence } \\
\text { (1 point) }\end{array}$ & $\begin{array}{l}\text { No } \\
\text { Evidence } \\
\text { (0 point) }\end{array}$ & Pts \\
\hline $\begin{array}{l}\text { KNOWLEDGE/ CONTENT } \\
\text { [Domain 1] } \\
\text { HOW WELL did students demonstrate } \\
\text { foundational knowledge/ content on this } \\
\text { topic? }\end{array}$ & & & & & & /3.0 \\
\hline $\begin{array}{l}\text { LEVEL OF EVIDENCE (literature, references, } \\
\text { citations) [Domain 1] } \\
\text { HOW WELL (to what degree) did students } \\
\text { provide literature citation(s)/ reference(s)? }\end{array}$ & & & & & & $/ 3.0$ \\
\hline $\begin{array}{l}\text { APPLY/ INTERPRET/ COMPARE/ CONTRAST/ } \\
\text { ANALYZE [Domain 1] } \\
\text { HOW WELL did students APPLY, INTERPRET, } \\
\text { COMPARE/ CONTRAST, ANALYZE applicable } \\
\text { literature? }\end{array}$ & & & & & & /3.0 \\
\hline $\begin{array}{l}\text { VISUAL AIDS/ EDUCATE AUDIENCE [Domain } \\
\text { 3] } \\
\text { HOW WELL did students use VISUAL AIDS to } \\
\text { educate audience? }\end{array}$ & & & & & & $/ 3.0$ \\
\hline $\begin{array}{l}\text { COMMUNICATION: DELIVERY \& } \\
\text { ARTICULATION [Domain 3] } \\
\text { HOW WELL did students deliver and } \\
\text { articulate their arguments? }\end{array}$ & & & & & & $/ 3.0$ \\
\hline $\begin{array}{l}\text { ACTIVE LISTENING / RESPONSES } \\
\text { [Domain 3] } \\
\text { HOW WELL did students actively listen and } \\
\text { actively respond? }\end{array}$ & & & & & & /3.0 \\
\hline $\begin{array}{l}\text { PROBLEM SOLVING \& CRITICAL THINKING } \\
\text { [Domain 3] } \\
\text { HOW WELL did students demonstrate } \\
\text { problem solving and critical thinking? }\end{array}$ & & & & & & $/ 3.0$ \\
\hline $\begin{array}{l}\text { LEADERSHIP and TEAMWORK [Domain 4] } \\
\text { HOW WELL did students demonstrate } \\
\text { leadership and teamwork? }\end{array}$ & & & & & & $/ 3.0$ \\
\hline $\begin{array}{l}\text { PROFESSIONALISM } \\
\text { [Domain 4] } \\
\text { HOW WELL did students demonstrate } \\
\text { professionalism? }\end{array}$ & & & & & & /3.0 \\
\hline $\begin{array}{l}\text { OVERALL PERFORMANCE } \\
\text { [Domain 4] } \\
\text { HOW WELL did students perform OVERALL? }\end{array}$ & $\begin{array}{l}\text { STRONG and } \\
\text { EXCELLENT } \\
\text { PERFORMANCE - } \\
\text { EXTREMELY } \\
\text { WELL PREPARED } \\
\text { (3 points) }\end{array}$ & $\begin{array}{l}\text { VERY GOOD } \\
\text { PERFORMANCE } \\
\text { - WELL } \\
\text { PREPARED } \\
\text { (2.5 points) }\end{array}$ & $\begin{array}{l}\text { GOOD } \\
\text { PERFORMANCE } \\
\text { - PREPARED } \\
\text { (1.5 points) }\end{array}$ & $\begin{array}{l}\text { LOW LEVEL } \\
\text { PERFORMANCE } \\
\text { - NOT } \\
\text { ADEQUATELY } \\
\text { PREPARED } \\
\text { (1 point) }\end{array}$ & $\begin{array}{l}\text { INADEQUATE } \\
\text { PERFORMANCE } \\
\text { - UNPREPARED - } \\
\text { NO EVIDENCE } \\
\text { (0 points) }\end{array}$ & $/ 3.0$ \\
\hline Total Points & & & & & & $/ 30$ \\
\hline
\end{tabular}

Judge's/Juror's Name:

Comments: 